OPEN ACCESS

Edited by:

Penghao Wang,

Murdoch University, Australia

Reviewed by:

Lingyan Zhou,

East China Normal University, China

Deepak Jaiswal,

University of Illinois

at Urbana-Champaign, United States

Xin Qiao,

ZJUT, China

${ }^{*}$ Correspondence:

Dan Wang

wangdan@nuist.edu.cn

Specialty section:

This article was submitted to Technical Advances in Plant Science,

a section of the journal

Frontiers in Plant Science

Received: 22 December 2020

Accepted: 04 March 2021

Published: 25 March 2021

Citation:

Cai Y, Miao Y, Wu H and Wang D (2021) Hyperspectral Estimation Models of Winter Wheat Chlorophyll

Content Under Elevated $\mathrm{CO}_{2}$.

Front. Plant Sci. 12:642917.

doi: 10.3389/fp/s.2021.642917

\section{Hyperspectral Estimation Models of Winter Wheat Chlorophyll Content Under Elevated $\mathrm{CO}_{2}$}

\author{
Yao Cai, Yuxuan Miao, Hao Wu and Dan Wang*
}

Department of Ecology, College of Applied Meteorology, Nanjing University of Information Science and Technology, Nanjing, China

Chlorophyll content is an important indicator of winter wheat health status. It is valuable to investigate whether the relationship between spectral reflectance and the chlorophyll content differs under elevated $\mathrm{CO}_{2}$ condition. In this open-top chamber experiment, the $\mathrm{CO}_{2}$ treatments were categorized into ambient $\left(\mathrm{aCO}_{2}\right.$; about $\left.400 \mu \mathrm{mol} \cdot \mathrm{mol}^{-1}\right)$ or elevated $\left(\mathrm{eCO}_{2}\right.$; ambient $\left.+200 \mu \mathrm{mol} \cdot \mathrm{mol}^{-1}\right)$ levels. The correlation between the spectral reflectance and the chlorophyll content of the winter wheat were analyzed by constructing the estimation model based on red edge position, sensitive band and spectral index methods, respectively. The results showed that there was a close relationship between chlorophyll content and the canopy spectral curve characteristics of winter wheat. Chlorophyll content was better estimated based on sensitive spectral bands and difference vegetation index (DVI) under both $\mathrm{aCO}_{2}$ and $\mathrm{eCO}_{2}$ conditions, though the accuracy of the models varied under different $\mathrm{CO}_{2}$ conditions. The results suggested that the hyperspectral measurement can be effectively used to estimate the chlorophyll content under both $\mathrm{aCO}_{2}$ and $\mathrm{eCO}_{2}$ conditionsand could provide a useful tool for monitoring plants physiology and growth. Keywords: elevated $\mathrm{CO}_{2}$, hyperspectral estimation model, chlorophyll content, red edge position, sensitive band,
spectral index, winter wheat

\section{INTRODUCTION}

It is expected that the atmospheric $\mathrm{CO}_{2}$ concentration will rise to $550 \mu \mathrm{mol} \cdot \mathrm{mol}^{-1}$ in 2050 and reach or exceed $700 \mu \mathrm{mol} \cdot \mathrm{mol}^{-1}$ at the end of the $21 \mathrm{st}$ century due to the increase of human population, energy production and utilization, deforestation and other intensive human activities (IPCC, 2013). Wheat is one of the world's most productive and important crops in the 21st century, and also the main source of food for human (Curtis and Halford, 2014). Under elevated $\mathrm{CO}_{2}$, the physiology, growth and yield of wheat and other species are affected (Long et al., 2006; Wang et al., 2012).

Chlorophyll content was closely related to crop health, photosynthetic capacity and crop yield (Lukas et al., 2014). $\mathrm{C}_{3}$ plants are more sensitive to elevated $\mathrm{CO}_{2}$ than $\mathrm{C}_{4}$ plants (Leakey et al., 2009). The chlorophyll content and photosynthetic rate of varieties of $C_{3}$ species, including crops and trees, was increased by elevated $\mathrm{CO}_{2}$ (Zhang et al., 2013; Madhana et al., 2014; Fathurrahman et al., 2016; Choi et al., 2017). For wheat, previous studies had shown a positive (Dubey et al., 2015) or negative (Wang et al., 2013) $\mathrm{CO}_{2}$ effects on the chlorophyll content and the difference might be resulted from the different experimental settings or $\mathrm{CO}_{2}$ increasing levels used in different studies. 
Given that systematic measurement of chlorophyll contents in elevated $\mathrm{CO}_{2}$ condition is scarce, a detailed measurement of chlorophyll content of winter wheat throughout the growing season will be useful to understand the effect of elevated $\mathrm{CO}_{2}$ on the physiology and growth of winter wheat.

Remote sensing methods could be used to accurately and rapidly relate variations in leaf optical properties with important plant characteristics, such as chlorophyll content and photosynthetic properties at the leaf and canopy scales (Ainsworth et al., 2014). Inversion of chlorophyll content by hyperspectral remote sensing was of great significance for crop growth status monitoring, yield estimation and agricultural planning (Liang et al., 2012; Flores-De-Santiago et al., 2013). Hyperspectral remote sensing had been used to monitor winter wheat chlorophyll content (He et al., 2018; Kasim et al., 2018). However, the application had been limited to specific test conditions (Serbin et al., 2012; Zhou et al., 2016) and there were few studies investigating hyperspectral remote sensing applications on winter wheat under elevated $\mathrm{CO}_{2}$ conditions.

The hyperspectral estimation models could be determined through different techniques to extract hyperspectral characteristics, including reflectance spectrum and first derivative spectrum, absorption and reflection location and vegetation index (Li et al., 2014). Previous research studied the relationship between visible and near-infrared spectra and leaf chemical components and found out that the original spectral reflectance and the first and second derivatives of the spectra could be used to estimate crop agronomic parameters (Card et al., 1988). Red edge and sensitive bands based spectral models had been used to simulate chlorophyll and nitrogen content of many species (Hansen and Schjoerring, 2003; Chen et al., 2013; Clevers and Gitelson, 2013; Stratoulias et al., 2015). Identifying optimal hyperspectral estimation models of winter wheat under different $\mathrm{CO}_{2}$ conditions is critical in crop growth monitoring and forecasting and requires further investigation.

In order to find an optimal estimation model for chlorophyll content and promote spectral analysis in the application of agriculture management under future global change conditions, an open top chamber (OTC) based $\mathrm{CO}_{2}$ manipulation experiment was conducted for 2 years in this study. The objectives of this study were: (1) to establish statistical models to study the relationship between hyperspectral characteristics and chlorophyll content of winter wheat throughout the growing stages; (2) to investigate whether the relationship between hyperspectral characteristics and chlorophyll content varies under elevated $\mathrm{CO}_{2}$ conditions.

\section{MATERIALS AND METHODS}

\section{Experimental Site}

The study site was located in the agrometeorological experimental station of Nanjing University of Information Science and Technology, in Nanjing city, Jiangsu province of China $\left(32^{\circ} 16^{\prime} \mathrm{N}, 118^{\circ} 86^{\prime} \mathrm{E}\right)$. The climate in this region characterizes subtropical monsoon season, with annual average precipitation of $1,100 \mathrm{~mm}$, the average temperature in recent years of $15.6^{\circ} \mathrm{C}$ and the average annual frost-free period of 237 days. The soil texture in the tillage layer of winter wheat was loamy clay, and the clayey content was $26.1 \%$. The bulk density of $0-20 \mathrm{~cm}$ soil was $1.57 \mathrm{~g} \cdot \mathrm{cm}^{-3}$, the $\mathrm{pH}\left(\mathrm{H}_{2} \mathrm{O}\right)$ value was 6.3 , and the organic carbon and total nitrogen content were 11.95 and $1.19 \mathrm{~g} \cdot \mathrm{kg}^{-1}$, respectively.

\section{Experimental Design}

Open top chambers (OTC) were used in the experiment to manipulate $\mathrm{CO}_{2}$ concentration. There were eight OTC chambers, all of which were octagonal prisms (opposite side diameter 3.75 $\mathrm{m}$, height $3 \mathrm{~m}$, bottom area $10 \mathrm{~m}^{2}$ ) and equipped with aluminum alloy frames and toughened glass with high transmittance. There were two $\mathrm{CO}_{2}$ treatments, ambient $\mathrm{CO}_{2}\left(\mathrm{aCO}_{2}\right)$ and elevated $\mathrm{CO}_{2}\left(\mathrm{eCO}_{2}, \mathrm{aCO}_{2}+200 \mu \mathrm{mol} \cdot \mathrm{mol}^{-1}\right)$, each with four replicates. The treatment of elevated $\mathrm{CO}_{2}$ started from regreening stage and lasted to the end of growing stage.

In order to avoid the rapid loss of $\mathrm{CO}_{2}$ gas and reduce the experiment cost, the top opening of OTC was designed to tilt inward for $45^{\circ}$. The $\mathrm{CO}_{2}$ concentration in the chambers was controlled with an automatic control platform, composed of $\mathrm{CO}_{2}$ sensors, gas-supplying devices and automatic control system. Three wind-blowing fans were placed in each chamber to make the $\mathrm{CO}_{2}$ gas in the chamber evenly distributed. The $\mathrm{CO}_{2}$ sensor feeds back the $\mathrm{CO}_{2}$ concentration information in the chamber to the automatic control system every two seconds. The $\mathrm{CO}_{2}$ concentration averaged was $650 \pm 58 \mu \mathrm{mol} \cdot \mathrm{mol}^{-1}$ in elevated $\mathrm{CO}_{2}$ chambers and $455 \pm 42 \mu \mathrm{mol} \cdot \mathrm{mol}^{-1}$ in ambient chambers across two growing seasons.

The local winter wheat variety of Ningmai 13 was selected in the study. The field measurement of spectrum and chlorophyll was conducted in 2018-2019 and 2019-2020 growing seasons. During the whole growing stages, fertilizer and water management were carried out in the local conventional way.

\section{Spectrum Measurement}

The spectral reflectance of winter wheat was measured by Field Spec4 of American analytical spectral device (ASD). The wavelength range was set at 350-2,500 $\mathrm{nm}$. The sampling interval and resolution was set at 1.4 and $3 \mathrm{~nm}$ in the range of 350$1,000 \mathrm{~nm}$; and 2 and $10 \mathrm{~nm}$ in 1,001-2,500 nm, respectively. The reflectance of winter wheat at five growth stages (jointing, booting, heading, filling and maturity stage) was measured on sunny days at 10:00 a.m.-2:00 p.m. Field Spec4 needed to be preheated 30 min before measurement. During the measurement, the sensor probe was placed vertically downward, the field of view angle was $10^{\circ}$ and the probe was about $20 \mathrm{~cm}$ away from the top of the canopy. The measurement was carried out 10 times in different areas of an OTC. The reference white board was corrected immediately before and after the measurements in each chamber.

\section{Measurement of Chlorophyll Content}

At the same time as the spectral measurement, the chlorophyll content was measured by the portable chlorophyll meter SPAD502. Relevant studies have shown that soil and plant analyzer developrnent (SPAD) value was positively correlated with the 
total chlorophyll content, with the correlation coefficient up to 0.99 , and the SPAD value could be used to represent the chlorophyll content of plants (Costa et al., 2001; Uddling et al., 2007). When measuring the chlorophyll content, five wheat plants were selected at the corresponding position of canopy spectrum measurement, then SPAD values were measured for five times uniformly on the upper, middle and lower leaves of each plant, and the average value was taken as the chlorophyll content of this sample point. A total of 200 chlorophyll samples were measured in 2018-2019 and 120 samples in 2019-2020. Two years of data were combined together, among which 240 samples were selected to establish the models, and the remaining 80 samples were used to verify the models.

\section{Statistical Analyses}

View Specpro_6.0, Matlab_2017 and Origin_2018 were used to process and analyze the data. The spectral band range was set at 350-1,350 $\mathrm{nm}$, and the wavelength corresponding to the largest first-order differential value in the red edge range (680$760 \mathrm{~nm}$ ) was selected as the red edge position $\lambda \mathrm{r}$. The correlation analysis between canopy spectral reflectance and SPAD values of winter wheat was conducted, and the correlation coefficient was calculated to find out the sensitive bands. According to the original reflectance of winter wheat canopy, five common vegetation indexes were calculated. Each vegetation index had different characteristics. The normalized difference vegetation index (NDVI) was a common vegetation index and very sensitive to green vegetation. Ratio vegetation index (RVI) was sensitive to vegetation with high coverage. Difference vegetation index (DVI) and perpendicular vegetation index (PVI) were sensitive to the change of soil background. Optimizing soil and adjusting vegeta $\hat{y}_{\mathrm{i}}$ tion index (OSAVI) explained the changes in the optical characteristics of the background and corrected the sensitivity of NDVI to the soil background (Bannari et al., 2007; Yan et al., 2013). The calculation of each vegetation index was listed in Table 1.

Using the canopy spectral data of winter wheat, a regression estimation model with hyperspectral variables as independent variables and the chlorophyll content as dependent variables was established. Linear regression model was selected for all models:

$$
Y=a+b x
$$

In this study, the coefficient of determination $\left(R^{2}\right)$ and the root mean square error (RMSE) were used to verify the linear regression model. The higher coefficient of determination $\mathrm{R}^{2}$ and the smaller RMSE indicated a more accurate estimation model.

$$
\begin{aligned}
R^{2} & =\frac{\sum_{i=1}^{n}\left(\hat{y}_{i}-\bar{y}_{i}\right)^{2}}{\sum_{i=1}^{n}\left(y_{i}-\bar{y}_{i}\right)^{2}} \\
R M S E & =\sqrt{\frac{1}{n} \sum_{i=1}^{n}\left(\hat{y}_{i}-y_{i}\right)^{2}}
\end{aligned}
$$

Where $\hat{y}_{i}$ and $\mathrm{y}_{i}$ were the predicted values and measured values of the sample respectively, and $i$ was the average value of the measured values of the sample, and $\mathrm{n}$ was the number of samples.

\section{RESULTS}

\section{Chlorophyll Content}

The chlorophyll content in winter wheat under $\mathrm{aCO}_{2}$ and $\mathrm{eCO}_{2}$ in five growth stages was listed in Table 2. The chlorophyll content was lowest in the maturing stage and highest in the heading stage and varied under different $\mathrm{CO}_{2}$ treatments. At different growth stages, the effects of $\mathrm{eCO}_{2}$ on chlorophyll content of winter wheat were different. In booting and heading stage, $\mathrm{eCO}_{2}$ increased the chlorophyll content by $4.70-6.90 \%$; in jointing, filling and maturity stage, $\mathrm{eCO}_{2}$ decreased the chlorophyll content by $2.80-18.20 \%$. During the whole growth stage, the chlorophyll content under $\mathrm{aCO}_{2}$ was lower than that under $\mathrm{eCO}_{2}$ (Table 2).

\section{Canopy Spectral Reflectance}

The original spectral band range was set at 350-1,350 $\mathrm{nm}$ and

\begin{tabular}{|c|c|c|}
\hline Spectral index & Formulation & Authors \\
\hline NDVI & $N D V I=\left(R_{N I R}-R_{R E D}\right) /\left(R_{N I R}+R_{R E D}\right)$ & Rouse et al., 1973 \\
\hline $\mathrm{RVI}$ & $R V I=R_{N I R} / R_{R E D}$ & Jordan, 1969 \\
\hline DVI & $D V I=R_{N I R}-R_{R E D}$ & Richardson and Wiegand, 1977 \\
\hline PVI & $P V I=\left(R_{N I R}-10.489 \times R_{R E D}-6.604\right) / \sqrt{1+10.489^{2}}$ & Huete et al., 1985 \\
\hline OSAVI & OSAVI $=(1+0.16)\left(R_{N I R}-R_{R E D}\right) /\left(R_{N I R}+R_{R E D}+0.16\right)$ & Rondeaux et al., 1996 \\
\hline
\end{tabular}
the canopy spectral reflectance under $\mathrm{aCO}_{2}$ and $\mathrm{eCO}_{2}$ at different

TABLE 1 | The calculation of the vegetation indexes.

\begin{tabular}{|c|c|c|c|c|c|c|c|}
\hline Data composition & Jointing & Booting & Heading & Filling & Maturity & $S D$ & CV\% \\
\hline $\mathrm{aCO}_{2}$ & $48.04 \pm 2.53^{c}$ & $55.50 \pm 2.15^{b}$ & $57.42 \pm 4.35^{\mathrm{a}}$ & $55.32 \pm 3.78^{b}$ & $44.28 \pm 4.26^{d}$ & 7.33 & 14.70 \\
\hline $\mathrm{eCO}_{2}$ & $46.70 \pm 3.53^{d}$ & $58.10 \pm 4.97^{b}$ & $61.38 \pm 3.75^{\mathrm{a}}$ & $51.98 \pm 2.51^{c}$ & $36.20 \pm 7.36^{e}$ & 10.65 & 21.38 \\
\hline
\end{tabular}

TABLE 2 | The chlorophyll content of winter wheat.

$S D$ is the standard deviation and the $\mathrm{CV}(\%)$ is the coefficient of variation. Lowercase letters indicate significant levels ( $p<0.05)$. 

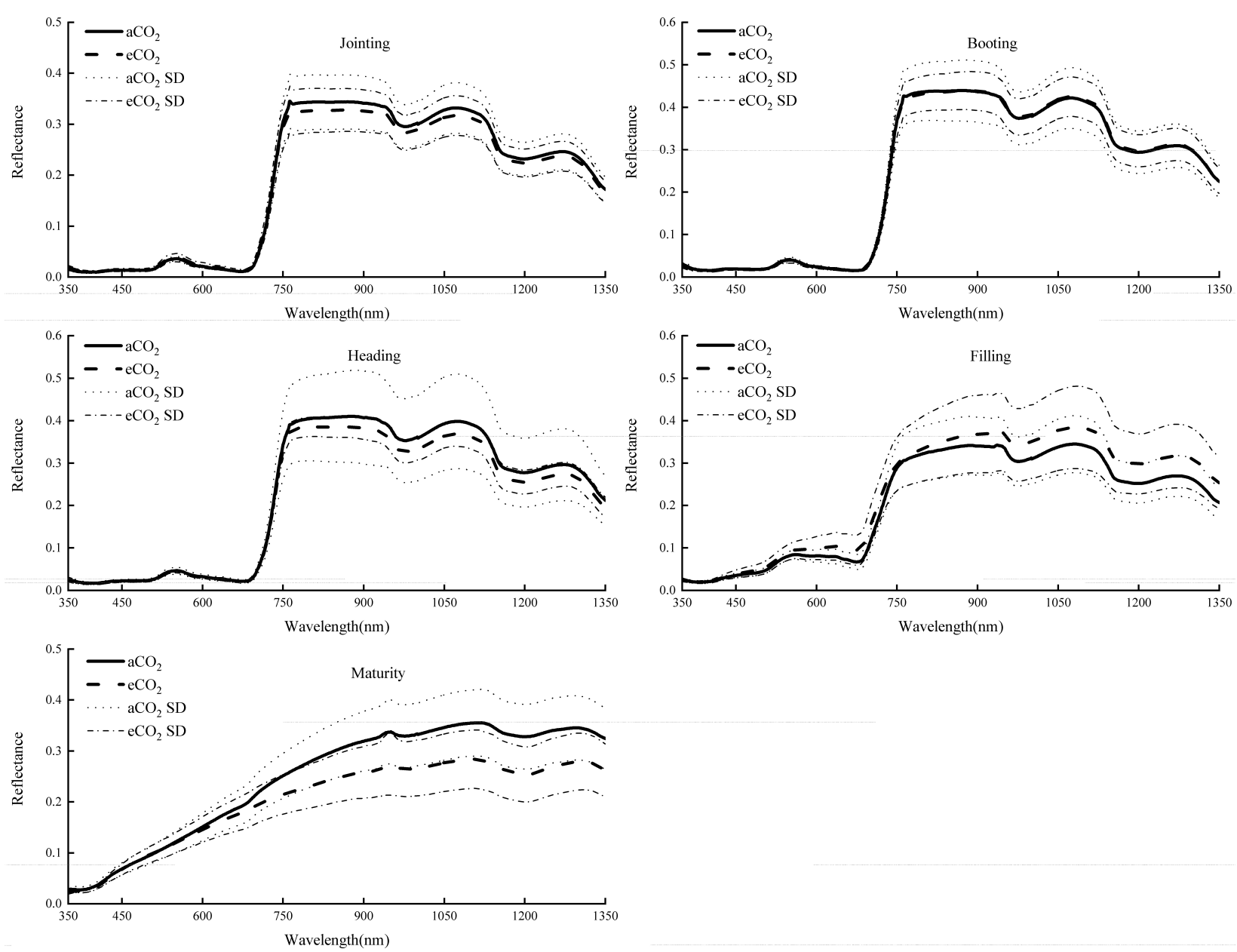

FIGURE 1 | Spectral reflectance of winter wheat canopy at different growing stages under $\mathrm{aCO}_{2}$ and $\mathrm{eCO}_{2}$.
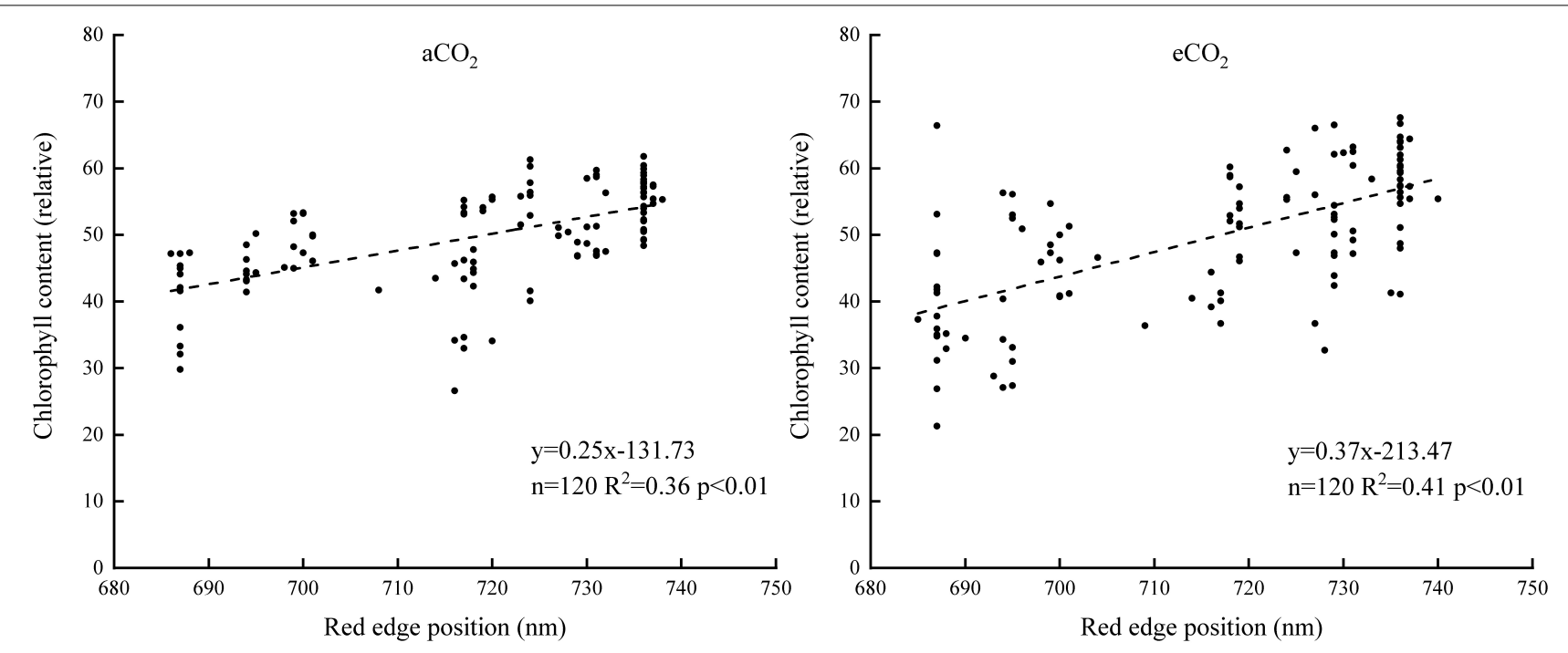

FIGURE 2 | The relationship between the chlorophyll content and the red-edge positions. 

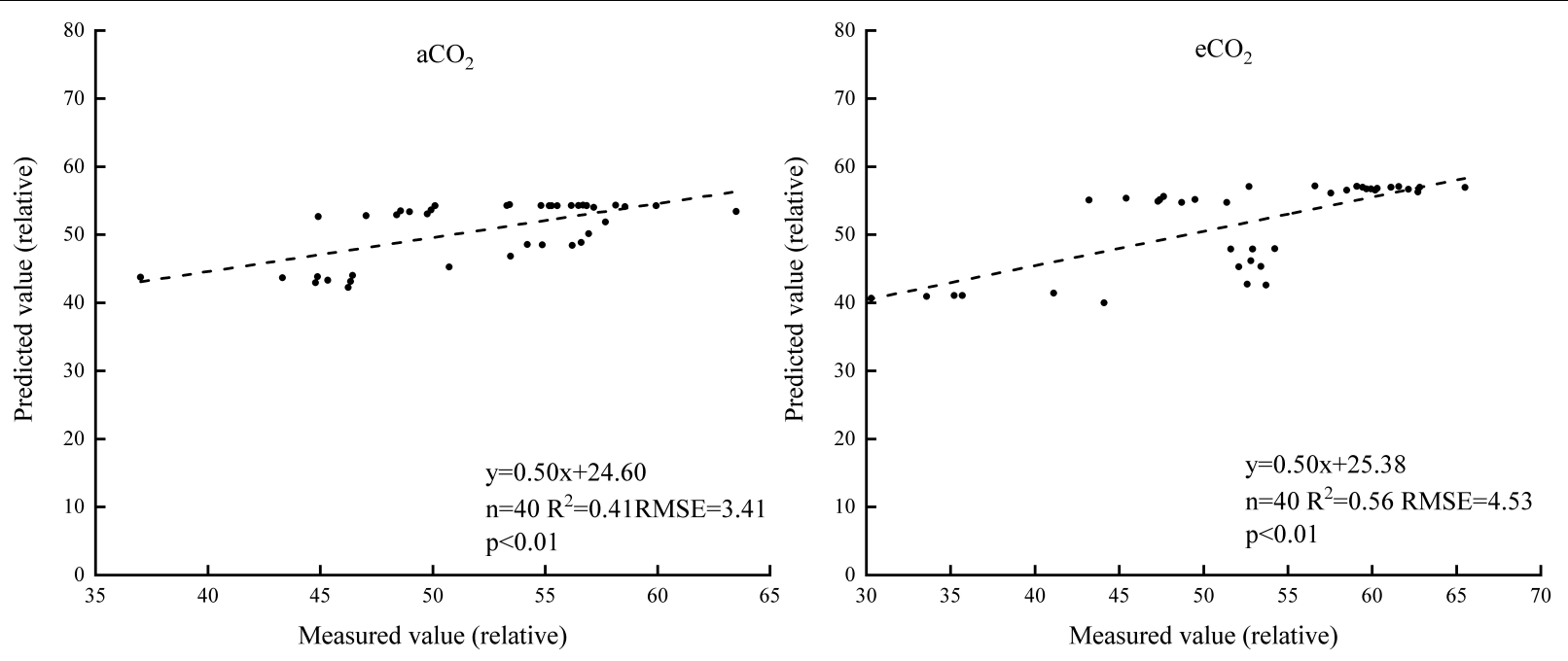

FIGURE 3 | The measured and estimated values of the chlorophyll content based on the red-edge position model under aCO $\mathrm{Cand}_{2} \mathrm{CO}_{2}$.

growth stages was shown in Figure 1. In each growth stage, the reflectance showed similar trend under $\mathrm{aCO}_{2}$ and $\mathrm{eCO}_{2}$, with an absorption band around $500 \mathrm{~nm}$, an obvious "green peak" around $550 \mathrm{~nm}$, the minimum value around $680 \mathrm{~nm}$, and a "red edge" within the band range of 680-760 $\mathrm{nm}$.

The spectral reflectance of winter wheat canopy under $\mathrm{eCO}_{2}$ was slightly lower at jointing, heading and maturity stages, and was higher at filling stage than that at $\mathrm{aCO}_{2}$, especially in the wavelength range of 760-1,350 $\mathrm{nm}$. In the booting stage, the spectral reflectance of the two treatments was similar. Among the five growth stages, the spectral reflectance at the booting stage was the highest, reaching about 0.45 .

\section{Chlorophyll Content Estimation Models The Red-Edge Position Model}

Spectral reflectance rose rapidly at about $680 \mathrm{~nm}$ and slowly at about $760 \mathrm{~nm}$. The band ranging between 680 and $760 \mathrm{~nm}$ was selected as the "red edge" spectrum. The linear regression model between the red edge position and the chlorophyll content was established to estimate chlorophyll content (Figure 2). The rest of the spectra and the chlorophyll content data were used to verify the model (Figure 3). The $R^{2}$ of the model was 0.36 and 0.41 under $\mathrm{aCO}_{2}$ and $\mathrm{eCO}_{2}$, respectively (Figure 2). The estimation model based on the red edge location estimated chlorophyll content slightly better under $\mathrm{eCO}_{2}$ than under $\mathrm{aCO}_{2}$ (Figure 3).

\section{The Sensitive Band Spectral Model}

The correlation coefficient of the spectral reflectance and chlorophyll content of winter wheat during the whole growth stage was analyzed (Figure 4). The correlation coefficient under $\mathrm{aCO}_{2}$ was higher than that under $\mathrm{eCO}_{2}$ between 350 and $1,350 \mathrm{~nm}$. The canopy reflectance had the greatest correlation with the chlorophyll content at 740 and $749 \mathrm{~nm}$ under $\mathrm{aCO}_{2}$ and $\mathrm{eCO}_{2}$, respectively.

The sensitive bands of 740 and $749 \mathrm{~nm}$ were then selected under $\mathrm{aCO}_{2}$ and $\mathrm{eCO}_{2}$ respectively, and the linear model between the spectral reflectance and chlorophyll content of the sensitive bands was established to estimate the chlorophyll content of winter wheat (Figure 5). The model was validated using the rest of the sampling data (Figure 6). The $\mathrm{R}^{2}$ of the linear model was 0.72 and 0.52 under $\mathrm{aCO}_{2}$ and $\mathrm{eCO}_{2}$, respectively (Figure 5) and the estimated values correlated well with the measured values of chlorophyll content under $\mathrm{aCO}_{2}$ and $\mathrm{eCO}_{2}$ (Figure 6).

\section{The Spectral Index Model}

Five different spectral indexes were extracted from the spectral reflectance curves (Table 2). Linear regression models of the five spectral indexes and chlorophyll contents of winter wheat were established. Under $\mathrm{aCO}_{2}$, the rank of $R^{2}$ of the linear models was DVI $>$ PVI $>$ OSAVI $>$ NDVI $>$ RVI. Under $\mathrm{eCO}_{2}$, the rank of the $R^{2}$ was DVI $>$ OSAVI $>$ NDVI $>$ PVI $>$ RVI

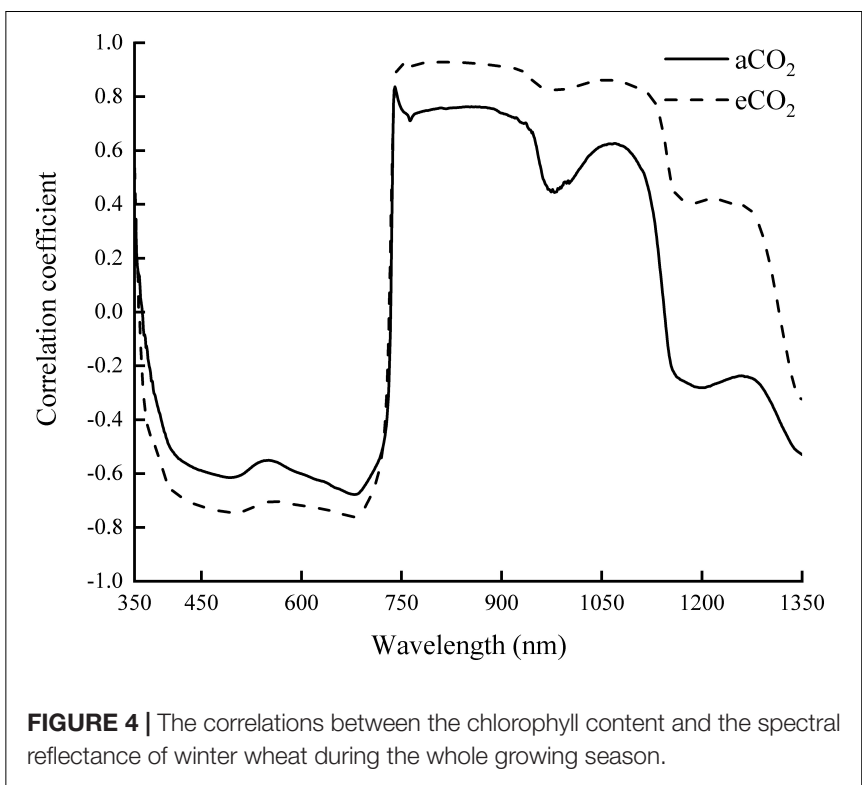



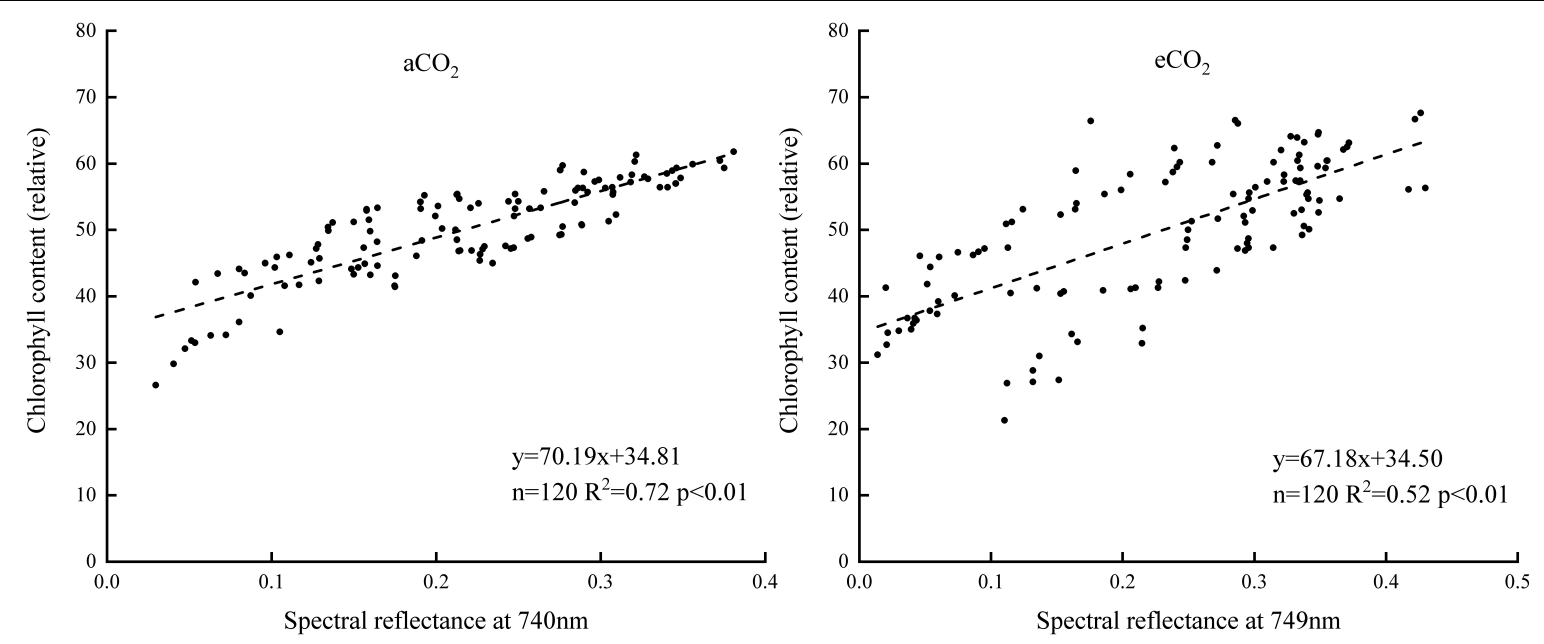

FIGURE 5| The relationship between the chlorophyll content and the sensitive bands position of the spectral reflectance.
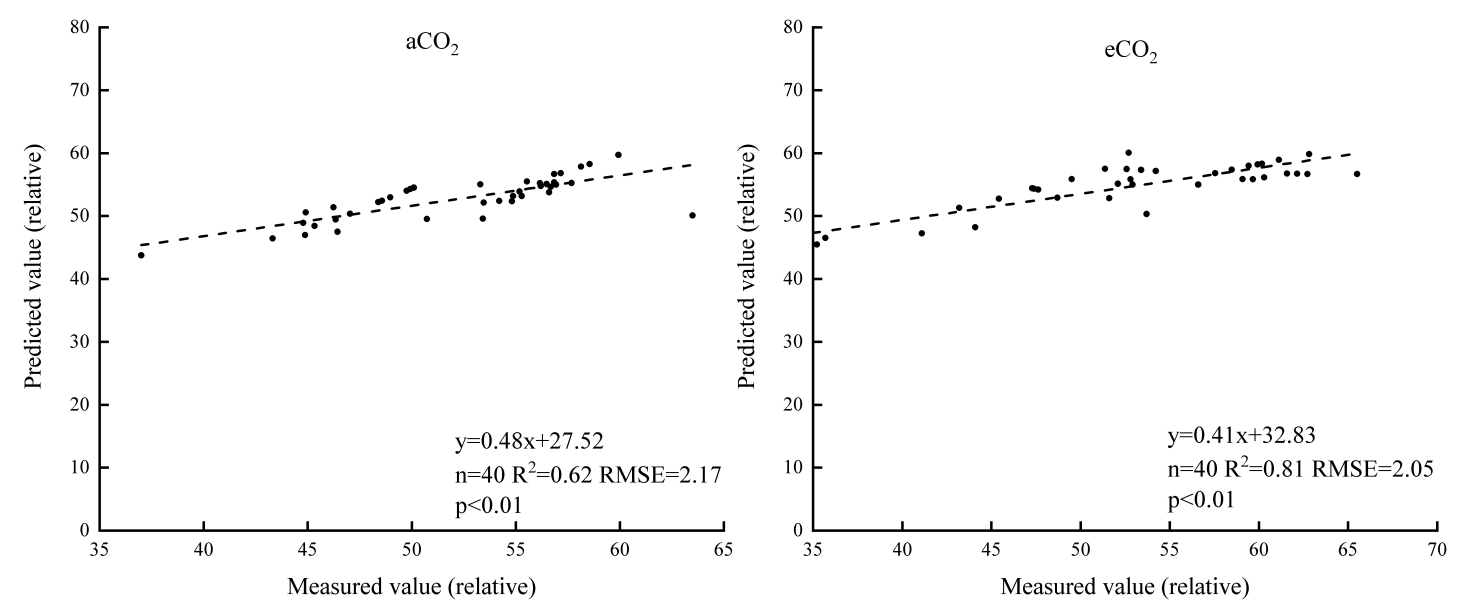

FIGURE 6 | The measured and estimated values of chlorophyll content based on the sensitive band position model under aCO $\mathrm{m}_{2}$ and $\mathrm{eCO}_{2}$

TABLE 3 | Estimation models of the chlorophyll content in wheat canopy based on different spectral indexes.

\begin{tabular}{lcccc}
\hline Treatment & Spectral index & Estimation equation & $\boldsymbol{R}^{\mathbf{2}}$ & Significance \\
\hline $\mathrm{aCO}_{2}$ & $\mathrm{NDVI}$ & $\mathrm{y}=19.10 \mathrm{x}+38.22$ & 0.56 & $p<0.01$ \\
& $\mathrm{RVI}$ & $\mathrm{y}=0.32 \mathrm{x}+46.38$ & 0.21 & $p<0.01$ \\
& $\mathrm{DVI}$ & $\mathrm{y}=0.39 \mathrm{x}+40.80$ & 0.67 & $p<0.01$ \\
& $\mathrm{PVI}$ & $\mathrm{y}=0.77 \mathrm{x}+34.28$ & 0.57 & $p<0.01$ \\
& $\mathrm{OSAVI}$ & $\mathrm{y}=16.53 \mathrm{x}+38.23$ & 0.56 & $p<0.01$ \\
& $\mathrm{NDVI}$ & $\mathrm{y}=27.83 x+32.82$ & 0.54 & $p<0.01$ \\
& $\mathrm{RVI}$ & $\mathrm{y}=0.50 \mathrm{x}+44.61$ & 0.22 & $p<0.01$ \\
& $\mathrm{DVI}$ & $\mathrm{y}=0.58 \mathrm{x}+37.31$ & 0.60 & $p<0.01$ \\
& $\mathrm{PVI}$ & $\mathrm{y}=0.71 \mathrm{x}+36.72$ & 0.30 & $p<0.01$ \\
& $\mathrm{OSAVI}$ & $\mathrm{y}=24.04 \mathrm{x}+32.89$ & 0.54 & $p<0.01$ \\
\hline
\end{tabular}

(Table 3). The DVI based estimation models was established using half of the measured data (Figure 7) and validated using the rest of the sampling data (Figure 8). The $R^{2}$ of the linear model established was 0.67 under $\mathrm{aCO}_{2}$ and 0.60 at $\mathrm{eCO}_{2}$ (Figure 7) and the estimated correlated well with the measured values of chlorophyll content under $\mathrm{aCO}_{2}$ and $\mathrm{eCO}_{2}$ (Figure 8).

\section{DISCUSSION}

In order to establish statistical models to study the relationship between the optical properties and chlorophyll content of winter wheat under elevated $\mathrm{CO}_{2}$ conditions, we measured the chlorophyll content and spectral reflectance in winter wheat canopy under $\mathrm{aCO}_{2}$ and $\mathrm{eCO}_{2}$ conditions throughout the growing season for 2 years. The effects of elevated $\mathrm{CO}_{2}$ on the chlorophyll content and spectral reflectance depended upon growing stages. The statistical models established in this study was effective under both ambient and elevated $\mathrm{CO}_{2}$ conditions. 

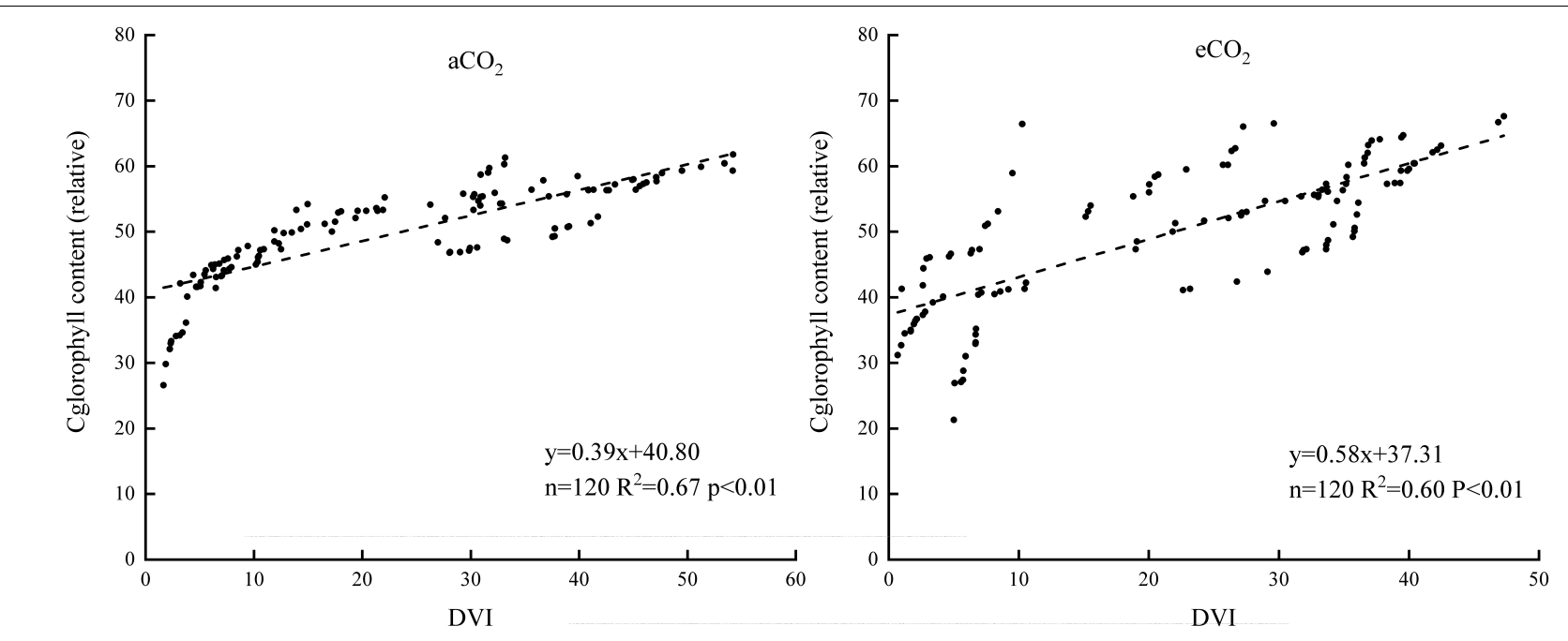

FIGURE 7 | The relationship between the chlorophyll content and the DVI.

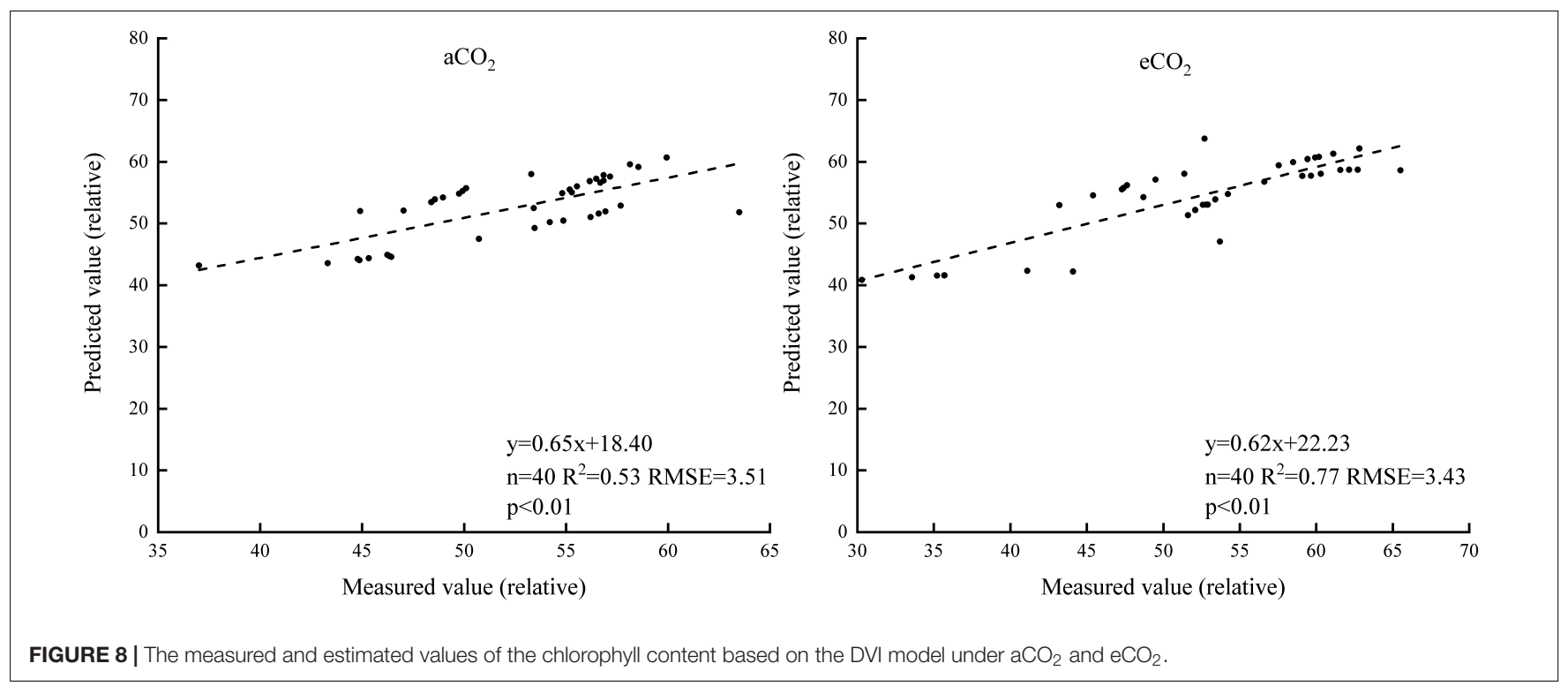

Elevated $\mathrm{CO}_{2}$ increased the chlorophyll content of winter wheat at booting and heading stage, but decreased it at filling and maturity stage in this study. Elevated $\mathrm{CO}_{2}$ usually had a positive effect on the chlorophyll content, but the specific effect depended on treatment duration and different species (Long et al., 2004). The increase of $\mathrm{CO}_{2}$ concentration in the late growing stage might lead to the faster decline of chlorophyll concentration of wheat (Ommen et al., 1999). In this study, the senescence of winter wheat under $\mathrm{eCO}_{2}$ was faster than that under $\mathrm{aCO}_{2}$ and the chlorophyll content was decreased under $\mathrm{eCO}_{2}$ at the later growing stages. The overall shapes of spectral curves did not change throughout the growing season, except in the maturity stage, the curves flattened due to the senescence of the leaves. The effect of elevated $\mathrm{CO}_{2}$ on the spectral curves varied at different growing stages, with no impact in the earlier jointing and boosting stages, positive impact in the filling and negative impact in the heading and maturity stages. Though elevated $\mathrm{CO}_{2}$ changed the maximum reflectance, it did not change the overall shape of the spectral curves of winter wheat at all the growing stages. The results were consistent with previous studies where the shapes of soybean canopy spectral curve did not change under different $\mathrm{CO}_{2}$ treatments (Gray et al., 2010) and $\mathrm{O}_{3}$ concentrations (Campbell et al., 2007).

Red edge position, sensitive band and vegetation index were effective means to retrieve crop chlorophyll content from the spectral curves (Dou et al., 2018; Kasim et al., 2018; Wang et al., 2019). Previous studies had shown that the position and reflectance of red edge were highly correlated with chlorophyll content of plant leaves and could be used as an indicator of chlorophyll content (Filella and Penuelas, 1994; Gitelson et al., 1996). The current study showed that the reflectance at the 
680-740 nm wavelengths had a positive relationship with the content of chlorophyll under both ambient and elevated $\mathrm{CO}_{2}$.

Sensitive bands could be used to calculate spectral indexes, which were sensitive to the difference of chlorophyll concentration in plant canopy (Hunt et al., 2011). The current results showed that the sensitive bands at 740 and $749 \mathrm{~nm}$ wavelength correlated with the chlorophyll content most, under $\mathrm{aCO}_{2}$ and $\mathrm{eCO}_{2}$, respectively (Figures 4-6), even though the established model fit slightly better under $\mathrm{aCO}_{2}$ than at $\mathrm{eCO}_{2}$ conditions. Vegetation indexes calculated from hyperspectral remote sensing technology had long been used to monitor the chlorophyll content of vegetation leaves (Meng et al., 2012; Guo et al., 2020). Among the five tested vegetation indexes, the DVI based model simulated the chlorophyll content best under both $\mathrm{aCO}_{2}$ and $\mathrm{eCO}_{2}$ conditions and the model using overall data from both the $\mathrm{CO}_{2}$ treatments gave similar results (results not shown). Though the methods tested in the study proved effective to simulate winter wheat chlorophyll content under different $\mathrm{CO}_{2}$ conditions, further investigations on how the spectral reflectance correlates with other biochemical contents and biophysical processes are still urgently needed for the purpose of guiding crop management and monitoring crop growth status in the future climate change situations.

In conclusion, the hyperspectral estimation models based on the red edge position, sensitive band and DVI vegetation index could all simulate the chlorophyll content of winter wheat. The accuracy of vegetation index and sensitive bands based models was higher than that of the red edge position model. The results suggested that the hyperspectral measurement can be effectively used to estimate the chlorophyll content under both $\mathrm{aCO}_{2}$ and $\mathrm{eCO}_{2}$ conditions and different equations should be established at specific $\mathrm{CO}_{2}$ growing conditions based on the methods chosen. The findings in the study were useful in providing hyperspectral

\section{REFERENCES}

Ainsworth, E. A., Serbin, S. P., Skoneczka, J. A., and Townsend, P. A. (2014). Using leaf optical properties to detect ozone effects on foliar biochemistry. Photosynth. Res. 119, 65-76. doi: 10.1007/s11120-013-9837-y

Bannari, A., Khurshid, K. S., Staenz, K., and Schwarz, J. W. (2007). A comparison of hyperspectral chlorophyll indices for wheat crop chlorophyll content estimation using laboratory reflectance measurements. IEEE Trans. Geosci. Remote Sens. 45, 3063-3074. doi: 10.1109/TGRS.2007.897429

Campbell, P. K. E., Middleton, E. M., Mcmurtrey, J. E., Crop, L. A., and Chappelle, E. W. (2007). Assessment of vegetation stress using reflectance or fluorescence measurements. J. Environ. Qual. 36, 832-845. doi: 10.2134/jeq2005.0396

Card, D. H., Peterson, D. L., Matson, P. A., and Aber, J. D. (1988). Prediction of leaf chemistry by the use of visible and near infrared reflectance spectroscopy. Remote Sens. Environ. 26, 123-147. doi: 10.1016/0034-4257(88)90092-2

Chen, B., Han, H. Y., Wang, F. Y., Liu, Z., and Xiao, C. H. (2013). Monitoring chlorophyll and nitrogen contents in cotton leaf infected by verticillium wilt with spectra red edge parameters. Acta Agron. Sin. 39:319. doi: 10.3724/SP.J. 1006.2013.00319

Choi, D., Watanabe, Y., Guy, R. D., Sugai, T., Toda, H., and Koike, T. (2017). Photosynthetic characteristics and nitrogen allocation in the black locust (Robinia pseudoacacia L.) grown in a FACE system. Acta Physiol. Plant. 39:71. doi: 10.1007/s11738-017-2366-0

Clevers, J. G. P. W., and Gitelson, A. A. (2013). Remote estimation of crop and grass chlorophyll and nitrogen content using red-edge bands on sentinel-2 and methods to monitor the growth status of winter wheat in the future global change situations.

\section{DATA AVAILABILITY STATEMENT}

The raw data supporting the conclusions of this article will be made available by the authors, without undue reservation.

\section{AUTHOR CONTRIBUTIONS}

DW designed and came up with the idea of the experiment. YC conducted the experiment, analyzed data, and wrote the manuscript. YM and HW helped in the field experiment and provided critical feedbacks on the manuscript. All authors contributed to the article and approved the submitted version.

\section{FUNDING}

This research was supported by the Nanjing University of Information Science and Technology (2013r115), Jiangsu Distinguished Professor Scholarship, Jiangsu six talent peaks (R2016L15), the Jiangsu Natural Science Foundation (BK20150894) and the National Natural Science Foundation of China (31500503 and 31770485) through DW.

\section{ACKNOWLEDGMENTS}

Wenhui Tao and Rui Kong help setting up and manage the experiment site.

-3. Int. J. Appl. Earth Observ. Geoinform. 23, 344-351. doi: 10.1016/j.jag.2012. 10.008

Costa, C., Dwyer, L. M., Dutilleul, P., Stewart, D. W., Ma, B. L., and Smith, D. L. (2001). Inter-relationships of applied nitrogen, spad, and yield of leafy and non-leafy maize genotypes. J. Plant Nutr. 24, 1173-1194. doi: 10.1081/PLN100106974

Curtis, T., and Halford, N. G. (2014). Food security: the challenge of increasing wheat yield and the importance of not compromising food safety. Ann. Appl. Biol. 164, 354-372. doi: 10.1111/aab.12108

Dou, Z. G., Cui, L. J., Li, J., Zhu, Y. N., Gao, C. J., and Pan, X. (2018). Hyperspectral estimation of the chlorophyll content in short-term and long-term restorations of mangrove in Quanzhou bay estuary, China. Sustainability 10:1127. doi: 10. 3390/su10041127

Dubey, S. K., Tripathi, S. K., and Pranuthi, G. (2015). Effect of elevated $\mathrm{CO}_{2}$ on wheat crop: mechanism and impact. Crit. Rev. Environ. Sci. Technol. 45, 2283-2304. doi: 10.1080/10643389.2014.1000749

Fathurrahman, F., Nizam, M. S., Juliana, W. A. W., Doni, F., and Radziah, C. M. Z. C. (2016). Growth improvement of rain tree (Albizia saman Jacq. Merr) seedlings under elevated concentration of carbon dioxide $\left(\mathrm{CO}_{2}\right)$. J. Pure Appl. Microbiol. 10, 1911-1917.

Filella, I., and Penuelas, J. (1994). The red edge position and shape as indicators of plant chlorophyll content, biomass and hydric status. Int. J. Remote Sens. 15, 1459-1470. doi: 10.1080/01431169408954177

Flores-De-Santiago, F., Kovacs, J. M., and Flores-Verdugo, F. (2013). The influence of seasonality in estimating mangrove leaf chlorophyll-a content from 
hyperspectral data. Wetl. Ecol. Manag. 21, 193-207. doi: 10.1007/s11273-0139290-x

Gitelson, A. A., Merzlyak, M. N., and Lichtenthaler, H. K. (1996). Detection of red edge position and chlorophyll content by reflectance measurements near 700 nm. J. Plant Physiol. 148, 501-508. doi: 10.1016/S0176-1617(96)80285-9

Gray, S. B., Dermody, O., and Delucia, E. H. (2010). Spectral reflectance from a soybean canopy exposed to elevated $\mathrm{CO}_{2}$ and $\mathrm{O}_{3}$. J. Exp. Bot. 61, 4413-4422. doi: $10.1093 /$ jxb/erq244

Guo, Y. H., Wang, H. X., Wu, Z. F., Wang, S. X., Sun, H. Y., and Senthilnath, J. (2020). Modified red blue vegetation index for chlorophyll estimation and yield prediction of maize from visible images captured by UAV. Sensors 20:5055. doi: 10.3390/s20185055

Hansen, P. M., and Schjoerring, J. K. (2003). Reflectance measurement of canopy biomass and nitrogen status in wheat crops using normalized difference vegetation indices and partial least squares regression. Remote Sens. Environ. 86, 542-553. doi: 10.1016/S0034-4257(03)00131-7

He, R. Y., Li, H., Qiao, X. J., and Jiang, J. B. (2018). Using wavelet analysis of hyperspectral remote-sensing data to estimate canopy chlorophyll content of winter wheat under stripe rust stress. Int. J. Remote Sens. 39, 4059-4076. doi: 10.1080/01431161.2018.1454620

Huete, A. R., Jackson, R. D., and Post, D. F. (1985). Spectral response of a plant canopy with different soil backgrounds. Remote Sens. Environ. 17, 37-53. doi: 10.1016/0034-4257(85)90111-7

Hunt, E. R., Daughtry, C., Eitel, J., and Long, D. (2011). Remote sensing leaf chlorophyll content using a visible band index. Agron. J. 103:1090. doi: 10.2134/ agronj2010.0395

IPCC (2013). Climate Change 2013: The Physical Science Basis. Contribution of Working Group I to the Fifth Assessment Report of the Intergovernmental Panel on Climate Change. Cambridge: Cambridge University Press.

Jordan, C. F. (1969). Derivation of leaf area index from quality of light on the forest floor. Ecology 50, 663-666. doi: 10.2307/1936256

Kasim, N., Sawut, R., Abliz, A., Shi, Q. D., Maihmuti, B., and Yalkun, A. (2018). Estimation of the relative chlorophyll content in spring wheat Based on an optimized spectral index. Photogramm. Eng. Remote Sens. 84, 801-811. doi: 10.14358/PERS.84.12.801

Leakey, A. D. B., Ainsworth, E. A., Bernacchi, C. J., Rogers, A., and Ort, D. R. (2009). Elevated $\mathrm{CO}_{2}$ effects on plant carbon, nitrogen, and water relations: six important lessons from FACE. J. Exp. Bot. 60, 2859-2876. doi: 10.1093/jxb/ erp096

Li, X. C., Zhang, Y. J., Bao, Y. S., Luo, J. H., Jin, X. L., and Xu, X. G. (2014). Exploring the best hyperspectral features for LAI estimation using partial least squares regression. Remote Sens. 6, 6221-6241. doi: 10.3390/rs60 76221

Liang, S., Zhao, G. X., and Zhu, X. C. (2012). Hyperspectral estimation models of chlorophyll content in apple leaves. Spectrosc. Spectr. Anal. 32, 1367-1370. doi: 10.3964/j.issn.1000-0593201205-1367-04

Long, S. P., Ainsworth, E. A., Leakey, A. D. B., Nösberger, J., and Ort, D. R. (2006). Food for thought: lower-than-expected crop yield stimulation with rising $\mathrm{CO}_{2}$ concentrations. Science 312, 1918-1921. doi: 10.1126/science.1114722

Long, S. P., Ainsworth, E. A., Rogers, A., and Ort, D. R. (2004). Rising atmospheric carbon dioxide: plants FACE the future. Annu. Rev. Plant Biol. 55, 591-628. doi: 10.1146/annurev.arplant.55.031903.141610

Lukas, V., Rodriguez-Moreno, F., Dryslova, T., and Neudert, L. (2014). Effectiveness of chlorophyll meter measurement in winter wheat at field scale level. Agriculture 60, 41-49. doi: 10.2478/agri-2014-0005

Madhana, S. K., Rachapudi, V. S., Mudalkar, S., and Reddy, A. R. (2014). Persistent stimulation of photosynthesis in short rotation coppice mulberry under elevated $\mathrm{CO}_{2}$ atmosphere. J. Photochem. Photobiol. B Biol. 137, 21-30. doi: 10.1016/j.jphotobiol.2014.05.001
Meng, Q. Y., Dong, H., Qin, Q. M., Wang, J. L., and Zhao, J. H. (2012). MTCARI: a kind of vegetation index monitoring vegetation leaf chlorophyll content based on hyperspectral remote sensing. Spectrosc. Spectr. Anal. 32, 2218-2222. doi: 10.3964/j.issn.1000-0593201208-2218-05

Ommen, O. E., Donnelly, A., Vanhoutvin, S., Vanoijen, M., and Manderscheid, R. (1999). Chlorophyll content of spring wheat flag leaves grown under elevated $\mathrm{CO}_{2}$ concentration and other environmental stresses within the ESPACE-wheat project. Eur. J. Agron. 10, 197-203. doi: 10.1016/s1161-0301(99)00011-8

Richardson, A. J., and Wiegand, C. L. (1977). Distinguishing vegetation from soil background information. Photogramm. Eng. Remote Sens. 43, 1541-1552. doi: 10.1109/TGE.1977.294499

Rondeaux, G., Steven, M., and Baret, F. (1996). Optimization of soil-adjusted vegetation indices. Remote Sens. Environ. 55, 95-107. doi: 10.1016/00344257(95)00186-7

Rouse, J. W., Haas, R. H., Schell, J. A., and Deering, D. W. (1973). “Monitoring vegetation systems in the great plains with ERTS," in Proceedings of the 3rd ERTS Symposium, NASA SP-351 (Washington, D.C: NASA Special Publication), 309-317.

Serbin, S. P., Dillaway, D. N., Kruger, E. L., and Townsend, P. A. (2012). Leaf optical properties reflect variation in photosynthetic metabolism and its sensitivity to temperature. J. Exp. Bot. 63, 489-502. doi: 10.1093/jxb/err294

Stratoulias, D., Balzter, H., Zlinszky, A., and Tóth, V. (2015). Assessment ofecophysiology of lake shore reed vegetation based on chlorophyll fluorescence, field spectroscopy and hyperspectral airborne imagery. Remote Sens. Environ. 157, 72-84. doi: 10.1016/j.rse.2014.05.021

Uddling, J., Gelang-Alfredsson, J., Piikki, K., and Pleijel, H. (2007). Evaluating the relationship between leaf chlorophyll concentration and SPAD-502 chlorophyll meter readings. Photosynth. Res. 91, 37-46. doi: 10.1007/s11120-006-9077-5

Wang, D., Heckathorn, S. A., Wang, X. Z., and Philpott, S. M. (2012). A metaanalysis of plant physiological and growth responses to temperature and elevated $\mathrm{CO}_{2}$. Oecologia 169, 1-13. doi: 10.1007/s00442-011-2172-0

Wang, L., Feng, Z. Z., and Schjoerring, J. K. (2013). Effects of elevated atmospheric $\mathrm{CO}_{2}$ on physiology and yield of wheat (Triticum aestivum L.): A meta-analytic test of current hypotheses. Agric. Ecosyst. Environ. 178, 57-63. doi: 10.1016/j. agee.2013.06.013

Wang, Y. M., Zhao, S. H., Cai, W. T., Heo, J., and Peng, F. C. (2019). A sensitive band to optimize winter wheat crop residue cover estimation by eliminating moisture effect. Sustainability 11, 1-18. doi: 10.3390/su11113032

Yan, F., Wu, B., and Wang, Y. J. (2013). Estimating aboveground biomass in Mu Us Sandy Land using Landsat spectral derived vegetation indices over the past 30 years. J. Arid Land 5, 521-530. doi: 10.1007/s40333-013-0180-0

Zhang, X. C., Yu, X. F., and Ma, Y. F. (2013). Effect of nitrogen application and elevated $\mathrm{CO}_{2}$ on photosynthetic gas exchange and electron transport in wheat leaves. Photosynthetica 51, 593-602. doi: 10.1007/s11099-013-0059-5

Zhou, X. F., Huang, W. J., Kong, W. P., Ye, H. C., and Luo, J. H. (2016). Remoteestimation of canopy nitrogen content in winter wheat using airbornehyperspectral reflectance measurements. Adv. Space Res. 58, 16271637. doi: 10.1016/j.asr.2016.06.034

Conflict of Interest: The authors declare that the research was conducted in the absence of any commercial or financial relationships that could be construed as a potential conflict of interest.

Copyright (c) 2021 Cai, Miao, Wu and Wang. This is an open-access article distributed under the terms of the Creative Commons Attribution License (CC BY). The use, distribution or reproduction in other forums is permitted, provided the original author(s) and the copyright owner(s) are credited and that the original publication in this journal is cited, in accordance with accepted academic practice. No use, distribution or reproduction is permitted which does not comply with these terms. 